\title{
Aflatoxin Contamination of Non-cultivated Fruits in Zambia
}

\author{
Paul W. Kachapulula1,2*, Ranajit Bandyopadhyay ${ }^{3}$ and Peter J. Cotty ${ }^{1 *}$ \\ ${ }^{1}$ USDA-ARS Aflatoxin Laboratory, School of Plant Sciences, The University of Arizona, Tucson, AZ, United States, ${ }^{2}$ Plant \\ Pathology Laboratory, School of Agricultural Sciences, Department of Plant Science, University of Zambia, Lusaka, Zambia, \\ ${ }^{3}$ International Institute of Tropical Agriculture (IITA), Ibadan, Nigeria
}

OPEN ACCESS

Edited by:

Mehdi Razzaghi-Abyaneh,

Pasteur Institute of Iran (PII), Iran

Reviewed by:

Kanniah Rajasekaran,

Agricultural Research Service (USDA),

United States

Ebrahim Hadavi

Islamic Azad University of Karaj, Iran

${ }^{*}$ Correspondence:

Paul W. Kachapulula

paul.kachapulula@unza.zm; paulwkachapulula@email.arizona.edu

Peter J. Cotty

cottypj@gmail.com

Specialty section:

This article was submitted to

Food Microbiology,

a section of the journal

Frontiers in Microbiology

Received: 22 April 2019

Accepted: 25 July 2019

Published: 09 August 2019

Citation:

Kachapulula PW,

Bandyopadhyay $R$ and Cotty PJ (2019) Aflatoxin Contamination

of Non-cultivated Fruits in Zambia.

Front. Microbiol. 10:1840.

doi: 10.3389/fmicb.2019.01840
Wild fruits are an important food and income source for many households in Zambia. Non-cultivated plants may be as susceptible as crops to aflatoxin contamination. Concentrations of aflatoxins in commonly consumed wild fruits from markets and characteristics of associated aflatoxin-producers need to be determined to assess the aflatoxin risk posed by handling, processing, storage, and consumption. Samples of Schinziophyton rautanenii $(n=22)$, Vangueriopsis lanciflora $(n=7)$, Thespesia garckeana $(n=17)$, Parinari curatellifolia $(n=17)$, Ziziphus spp. $(n=10)$, Adansonia digitata $(n=9)$, and Tamarindus indica $(n=23)$ were assayed for aflatoxin using lateral-flow immunochromatography from 2016 to 2017. Aflatoxins were above Zambia's regulatory limit $(10 \mu \mathrm{g} / \mathrm{kg}$ ) in S. rautanenii (average $=57 \mu \mathrm{g} / \mathrm{kg}$ ), V. lanciflora (average $=12 \mu \mathrm{g} / \mathrm{kg}$ ), and $T$. garckeana (average $=11 \mu \mathrm{g} / \mathrm{kg}$ ). The $\mathrm{L}$ strain morphotype of Aspergillus flavus was the most frequent member of Aspergillus section Flavi in market samples, although Aspergillus parasiticus and fungi with $S$ morphology were also found. All fruits except $T$. indica supported both growth (mean $=3.1 \times 10^{8} \mathrm{CFU} / \mathrm{g}$ ) and aflatoxin production (mean $=35,375 \mu \mathrm{g} / \mathrm{kg}$ ) by aflatoxigenic Aspergillus section Flavi. Innate resistance to aflatoxin producers was displayed by $T$. indica. For the other fruits, environment and infecting fungi appeared to have the greatest potential to influence aflatoxin concentrations in markets. This is the first report of aflatoxins and aflatoxin-producers on native fruits in Zambia and suggests mitigation is required.

Keywords: aflatoxin, Aspergillus, Schinziophyton, non-cultivated fruits, Zambia, food safety

\section{INTRODUCTION}

Wild fruits supplement diets and incomes of people in portions of rural Zambia (Kalaba et al., 2009). These fruits are gathered for direct consumption, especially during famines (Akinnifesi et al., 2008), and for sale in urban centers (Kalaba et al., 2009). More than 75 wild fruit species are consumed in Southern Africa (Akinnifesi et al., 2002; Kalaba et al., 2009), with some of the popular fruits being Parinari curatellifolia, Ziziphus mauritiana, Schinziophyton rautanenii, Uapaca kirkiana, and Anisophyllea boehmii (Zimba et al., 2005; Chadare et al., 2008; Kalaba et al., 2009). Wild fruits have various uses (Table 1) including processing into juice and porridge. Fruit seeds may be eaten as a snack or extracted for oil (Juliani et al., 2007; Chadare et al., 2008; Maroyi, 2011; Vermaak et al., 2011; Njana et al., 2013; Benhura et al., 2015; Rahul et al., 2015; Maruza et al., 2017). Consumption of wild fruits is expected to increase and efforts to domesticate wild fruit tree species are increasing (Akinnifesi et al., 2002; Akinnifesi et al., 2006). Approval of fruits as food ingredients 
by the European Commission and the U.S. Food \& Drug Administration has increased demand for wild fruits, e.g., Adansonia digitata, in the western world and is expected to outstrip supply (Buchmann et al., 2010; Buchwald-Werner and Bischoff, 2011). Food safety concerns associated with wild fruits affect consumers in both rural and urban areas.

Wild fruits will likely remain a vital component of diets and, as such, it is important to ensure these fruits are free of hazardous microbes and mycotoxins, such as aflatoxins (Boyd and Cotty, 2001). Consumption of food contaminated with aflatoxins can lead to liver cancer, immuno-suppression, stunting, reduced weight-gain, and rapid death in humans (Turner et al., 2003; Gong et al., 2004; Williams et al., 2004; Lewis et al., 2005; Probst et al., 2007; Reddy and Raghavender, 2007; Liu et al., 2012). Enforcement of aflatoxin regulatory limits result in loss of markets and reduced income (Van Egmond et al., 2007; Wu, 2014). The most commonly reported aflatoxin producers are Aspergillus flavus (produces only B aflatoxins) and Aspergillus parasiticus (produces both B and $G$ aflatoxins) (Horn and Dorner, 1998). However, several closely related taxa are known to contaminate crops in Africa including Aspergillus minisclerotigenes, Aspergillus aflatoxiformans, and an unnamed taxa associated with lethal aflatoxicosis in Kenya (Cotty et al., 2008; Probst et al., 2010; Frisvad et al., 2019; Singh and Cotty, 2019).

Aspergillus flavus and other aflatoxin-producers are frequently placed into one of two morphotypes based on sclerotial morphology. The L strain morphotype produces few large sclerotia (average diameter $>400 \mu \mathrm{m}$ ) and the $S$ strain morphotype produces numerous small sclerotia (average diameter $<400 \mu \mathrm{m}$ ) (Cotty, 1989). Fungi with $\mathrm{S}$ morphology frequently produce large quantities of aflatoxins and DNA based phylogenetic evidence suggests these aflatoxin-producers belong to several species: (a) A. flavus $\mathrm{S}$ strain; (b) Lethal Aflatoxicosis Fungus (LAF) $\mathrm{S}_{\mathrm{B}}$ that led to many deaths in Kenya (Probst et al., 2007); (c), A. aflatoxiformans (Cotty and Cardwell, 1999; Frisvad et al., 2019; Singh and Cotty, 2019); and (d) A. minisclerotigenes (Pildain et al., 2008).

Aflatoxin-producers infect and produce aflatoxins on both domestic and wild plant species (Boyd and Cotty, 2001). Differences exist among domesticated plants in susceptibility to both aflatoxin-producers and aflatoxin contamination (Mehl and Cotty, 2013a; Kachapulula et al., 2017a) and such variation is also expected among plants that have not been domesticated. Knowledge of plant species vulnerability to aflatoxin contamination may both inform aflatoxin mitigation efforts and facilitate the shaping of diets to limit aflatoxin exposure. In addition, aflatoxin-producer genotypes differ in aflatoxin-producing potential and the relative importance of specific etiologic agents may depend on region (Probst et al., 2007; Cotty et al., 2008). Aflatoxin levels and frequencies of aflatoxin-producers in wild fruits of Zambia have not been characterized.

In order to ascertain levels of aflatoxins and potential for contamination in wild fruits in Zambia, this study:
(1) Quantified aflatoxins in the wild fruits P. curatellifolia, Ziziphus spp., S. rautanenii, Tamarindus indica, Vangueriopsis lanciflora, Thespesia garckeana and A. digitata; (2) Characterized communities of Aspergillus section Flavi in the fruits; and (3) Assessed suitability of the fruits to support growth and aflatoxin production by aflatoxigenic Aspergillus section Flavi.

\section{MATERIALS AND METHODS}

\section{Sampling}

Samples of dried fruits (107 total) consisting of S. rautanenii $(n=22)$, P. curatellifolia $(n=17) V$. lanciflora $(n=7)$, Ziziphus spp. $(n=12), T$. indica $(n=23)$, A. digitata $(n=9)$ and T. garckeana ( $n=17$, Table 2 and Figures 1, 2) were collected from markets in 9 districts: Lusaka, Kaoma, Mongu, Senanga, Kapiri Mposhi, Mazabuka, Choma, Livingstone, and Sesheke. For each plant species, up to five fruit samples (350 to $500 \mathrm{~g}$ each, with multiple individual fruits in each fruit sample) were obtained from each market where the fruits were present with at least three markets sampled in each district. The fruits were dried at the University of Zambia in a forced air oven $\left(40^{\circ} \mathrm{C}\right)$ to $5-8 \%$ water content, to prevent fungal growth, and sealed in plastic bags to prevent rehydration. The remainder of the analyses were performed at the USDA, ARS, Laboratory in the School of Plant Sciences, The University of Arizona.

\section{Aflatoxin Quantification}

Total aflatoxins were quantified with a GIPSA approved lateral flow immunochromatographic assay (Reveal Q + for Aflatoxin, Neogen Corporation, Lansing, MI, United States) following modifications to the manufacturer's instructions recommended by GIPSA. Briefly, each entire dry fruit sample (350 to $500 \mathrm{~g}$ ) was ground with either a knife mill (Retsch GM200, Retsch GmbH, Haan, Germany) or cutting mill (Retsch SM100, Retsch GmbH, Haan, Germany) to pass at least $75 \%$ of the material through a 20 mesh sieve, mixed thoroughly, and a $50 \mathrm{~g}$ sub-sample was blended with $250 \mathrm{ml}$ of $65 \%$ ethanol. Aflatoxin content was determined according to the manufacturer's instructions on a dry weight basis. The aflatoxin quantification technique used was not designed for wild fruits, and as such, results were corrected by spike and recovery experiments done for each fruit. Briefly, ground fruit $(5 \mathrm{~g})$ with no detectable aflatoxin was spiked to $100 \mu \mathrm{g} / \mathrm{kg}$ of total aflatoxin using an aflatoxin standard (in methanol, Supelco, Bellefonte, PA, United States). Total aflatoxin was extracted and quantified as described above. Spike and recovery was performed in five replicates. Recovery rates were estimated using the following equation: $\%$ Recovery $=$ Total aflatoxin concentration measured in spiked sample/Spiked concentration $\times 100$. Precision of the analytical method was expressed as relative standard deviation (RSD) of replicated results. Recovery rates ranged from 40-60\%. Obtained aflatoxin concentrations were corrected to recovery. The limit of detection for Reveal $Q+$ for 
TABLE 1 | Uses of non-cultivated fruits frequently sold in local markets in Zambia.

\begin{tabular}{|c|c|c|c|}
\hline Fruit species & Common name & Uses & References \\
\hline Adansonia digitata & Baobab & $\begin{array}{l}\text { Fruit pulp used to make beverages, porridges. } \\
\text { Leaves, bark, and seeds medicinal }\end{array}$ & $\begin{array}{l}\text { Chadare et al., 2008; Rahul et al., 2015; } \\
\text { Vermaak et al., } 2011\end{array}$ \\
\hline Parinari curatellifolia & $\begin{array}{l}\text { Hissing tree, mobola plum, } \\
\text { cork tree }\end{array}$ & $\begin{array}{l}\text { Fruit pulp used to make beverages, porridges. } \\
\text { Leaf extracts medicinal. Seeds eaten as snacks } \\
\text { and used to extract oil }\end{array}$ & Akinnifesi et al., 2006; Benhura et al., 2015 \\
\hline Schinziophyton rautanenii & Mongongo, manketti & $\begin{array}{l}\text { Fruit pulp used to make beverages, porridges. } \\
\text { Seeds eaten as snacks and used to extract oil }\end{array}$ & Zimba et al., 2005; Vermaak et al., 2011 \\
\hline Tamarindus indica & Tamarind & $\begin{array}{l}\text { Fruit pulp used to make beverages, porridges. } \\
\text { Leaves are used in medicines and used in feed }\end{array}$ & Ebifa-Othieno et al., 2017 \\
\hline Thespesia garckeana & Snot apple & $\begin{array}{l}\text { Fruit pulp used to make beverages, porridges. } \\
\text { Medicinal }\end{array}$ & Maroyi, 2011 \\
\hline Vangueriopsis lanciflora & $\begin{array}{l}\text { False wild medlar, crooked } \\
\text { false medlar }\end{array}$ & Fruit pulp used to make beverages, porridges. & \\
\hline Ziziphus spp. & $\begin{array}{l}\text { Black date, Chinese date, } \\
\text { date seed, and several } \\
\text { others }\end{array}$ & Beverages, jams, cakes, medicinal & Maruza et al., 2017 \\
\hline
\end{tabular}

TABLE 2 | Aflatoxin in non-cultivated fruits purchased from local markets in Zambia.

\begin{tabular}{|c|c|c|c|c|c|c|c|}
\hline \multirow[t]{2}{*}{ Species } & \multirow[t]{2}{*}{ Samples (\#) } & \multicolumn{2}{|c|}{ Aflatoxin $(\mu \mathrm{g} / \mathrm{kg})$} & \multicolumn{4}{|c|}{ Samples in categories (\%) } \\
\hline & & Mean & Range $^{a}$ & $<4 \mu \mathrm{g} / \mathrm{kg}$ & $4-9.9 \mu \mathrm{g} / \mathrm{kg}$ & $10-19.9 \mu \mathrm{g} / \mathrm{kg}$ & $>20 \mu \mathrm{g} / \mathrm{kg}$ \\
\hline Adansonia digitata & 9 & $4^{\mathrm{BC}}$ & ND-7.5 & 66.7 & 33.3 & 0 & 0 \\
\hline Parinari curatellifolia & 17 & $6^{\mathrm{BC}}$ & ND-8.6 & 29.4 & 70.6 & 0 & 0 \\
\hline Schinziophyton rautanenii & 22 & $57^{\mathrm{A}}$ & $3.4-128.6$ & 4.5 & 13.6 & 9.1 & 72.8 \\
\hline Tamarindus indica & 23 & $3^{C}$ & ND-9.0 & 78.3 & 21.7 & 0 & 0 \\
\hline Thespesia garckeana & 17 & $11^{\mathrm{B}}$ & $3.9-23.2$ & 5.9 & 41.2 & 47.0 & 5.9 \\
\hline Vangueriopsis lanciflora & 7 & $12^{\mathrm{B}}$ & $6.6-18.9$ & 0 & 28.6 & 71.4 & 0 \\
\hline Ziziphus spp. & 10 & $6^{\mathrm{BC}}$ & ND-24.4 & 70.0 & 20.0 & 10.0 & 0 \\
\hline
\end{tabular}

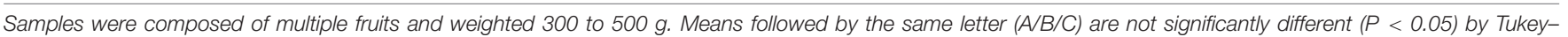
Kramer's HSD test. Limit of detection $=2 \mu \mathrm{g} / \mathrm{kg}$, Range of detection is $2-150 \mu \mathrm{g} / \mathrm{kg} .{ }^{a} \mathrm{ND}=$ non-detected.

Aflatoxin is $2 \mu \mathrm{g} / \mathrm{kg}$ and the range of detection is 2$150 \mu \mathrm{g} / \mathrm{kg}$.

\section{Isolation and Identification of Fungi From Fruits}

Dried fruit samples were ground in either a knife mill (T. indica, Ziziphus spp., A. digitata, V. lanciflora, Grindomix GM200, Retsch GmbH, Haan, Germany) or cutting mill (S. rautanenii, T. Garckeana, and P. curatellifolia; Retsch SM100, Retsch GmbH, Haan, Germany) to pass a \#12 sieve, and homogenized. Fungi were isolated from ground fruit material using dilution plate technique on modified rose Bengal agar (Cotty, 1994). Briefly, ground fruit material (0.1 to $10 \mathrm{~g}$ ) was shaken in $50 \mathrm{ml}$ sterile distilled water $(20 \mathrm{~min}$, $100 \mathrm{rpm}$ ) on a reciprocal shaker (KS-501, IKA Works Inc., Wilmington, NC, United States). Dilution plating was performed in triplicate. Plates were incubated ( 3 days, $31^{\circ} \mathrm{C}$, dark) and up to eight colonies of Aspergillus section Flavi per isolation were transferred to 5-2 agar (5\% V8-juice; 2\% agar, $\mathrm{pH}$ 5.2). Fungi were stored in sterile water $(2 \mathrm{ml})$ as plugs of sporulating culture after incubation for 7 days at $31^{\circ} \mathrm{C}$ (Cotty, 1988). Isolations were performed a minimum of twice

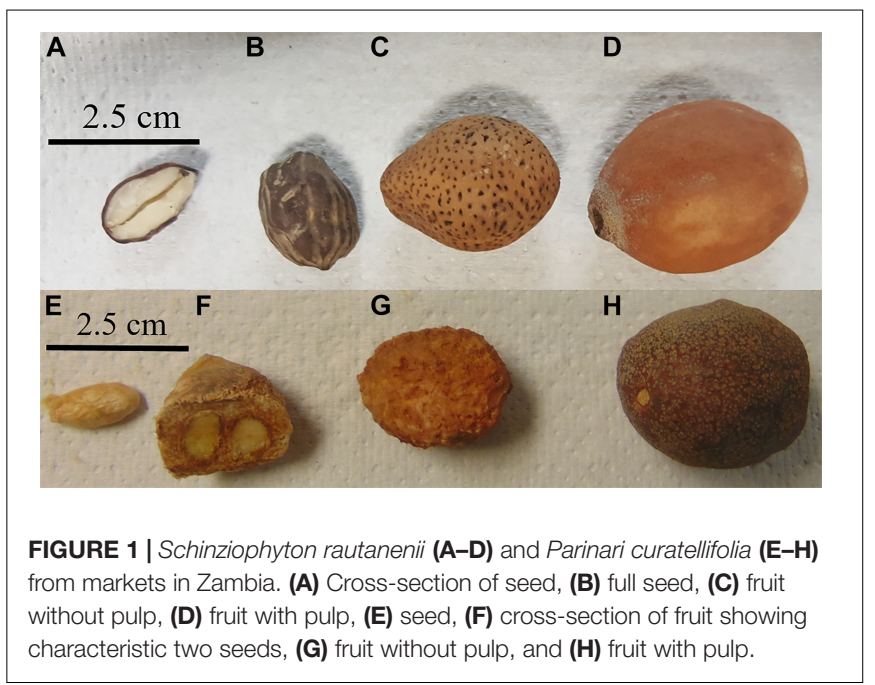

to obtain a total of at least 15 isolates from each sample. Aspergillus species and strains were identified using both macroscopic and microscopic characteristics (Klich and Pitt, 1988; Cotty, 1989, 1994; Probst et al., 2007). 


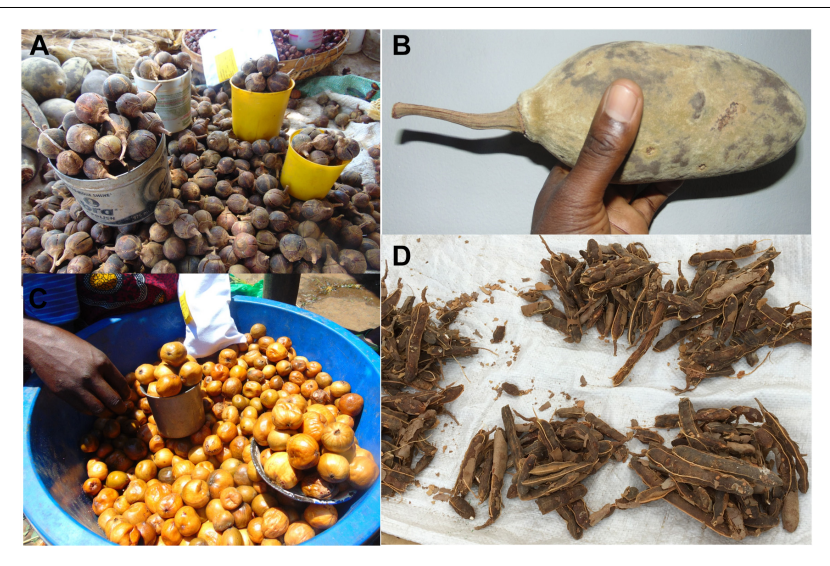

FIGURE 2 | Uncultivated fruits in markets. (A) Thespesia garckeana in $500 \mathrm{ml}$ (silver) and $200 \mathrm{ml}$ (yellow) containers, (B) Adansonia digitata,

(C) Vangueriopsis lanciflora, and (D) Piles of Tamarindus indica.

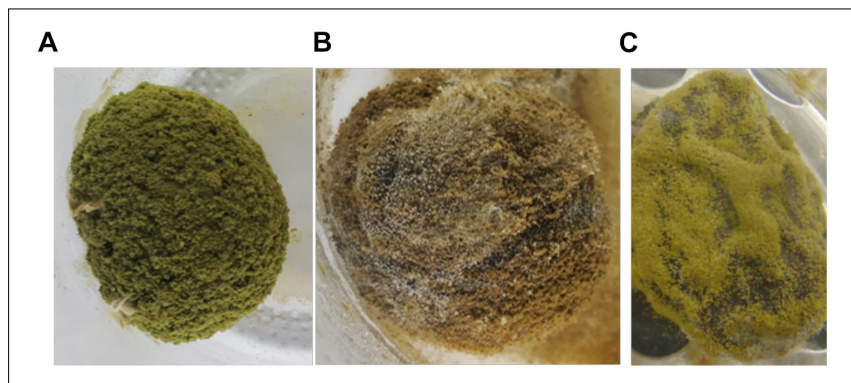

FIGURE 3 | Growth of Aspergillus section Flavi on inoculated fruits. (A) Aspergillus flavus L. morphotype on Parinari curatellifolia, (B) Aspergillus parasiticus on Thespesia garckeana, and (C) Aspergillus minisclerotigenes on Vangueriopsis lanciflora. All other fungi had similar growth on all fruits except on Tamarindus indica, which did not support fungal growth during these tests.

\section{Wild Fruits as Substrate for Growth and Aflatoxin Production}

To evaluate ability of wild fruit to support growth and aflatoxin contamination, colony forming units (CFU) and aflatoxin concentrations were measured on fruit previously inoculated with aflatoxigenic Aspergillus section Flavi. Briefly, five isolates representing the A. flavus L strain morphotype $(\mathrm{AF} 13=$ ATCC $96044=$ SRRC 1273) and the A. flavus S strain morphotype (AF70 = ATCC MYA384), A. parasiticus (NRRL 2999), A. minisclerotigenes (A-11611) and A. aflatoxiformans (A11612) were inoculated onto sterile whole fruits $(10 \mathrm{~g}$ in $250 \mathrm{ml}$ Erlenmeyer flask) previously autoclaved for $20 \mathrm{~min}$, cooled to room temperature and moisture adjusted to $30 \%$. The five isolates were chosen because they represent the main aflatoxin-producing species reported to cause aflatoxin contamination in Africa and have frequently been isolated from crops and soils in Africa where the wild fruits under study grow. Spore suspensions containing one million freshly harvested spores from 7-dayold cultures were used as inoculum. After incubation (7 days, $\left.100 \% \mathrm{RH}, 31^{\circ} \mathrm{C}\right), 100 \mathrm{ml}$ of $0.1 \%$ Tween 80 sterile distilled deionized water was added and flasks were shaken $(650 \mathrm{rpm}$, mini orbital shaker, Troemner LLC, Thorofare, NJ, United States) for $10 \mathrm{~min}$ to wash the conidia from the intact fruits. The resulting conidial suspension was subjected to a 10 -fold dilution series and plated onto rose Bengal agar in five replicates. The amount of conidia produced per gram of substrate were expressed on a dry weight basis. To quantify aflatoxin production, cultures were blended in $50 \mathrm{ml}$ of $70 \%$ methanol (20 s, maximum speed, Waring 7012S, Waring, Torrington, Connecticut). The slurry was allowed to settle $(20 \mathrm{~min})$ and $4 \mu \mathrm{l}$ of the supernatant was spotted directly onto thin-layer chromatography (TLC) plates (Silica gel 60, EMD, Darmstadt, Germany) adjacent to aflatoxin standards (Aflatoxin Mix Kit-M, Supelco, St. Louis, MO, United States) containing known quantities of aflatoxins $B_{1}, B_{2}, G_{1}$, and $G_{2}$. Plates were developed in 96:3:1 ethyl ether-methanol-water, air-dried, and aflatoxins were visualized under 365-nm UV light. Aflatoxins were quantified directly on TLC plates using a scanning densitometer (TLC Scanner 3, Camag Scientific Inc., Wilmington, NC, United States) running winCATS 1.4.2 (Camag Scientific Inc., Wilmington, NC, United States). The limit of detection and range of detection for the aflatoxin quantification technique used was $5 \mu \mathrm{g} / \mathrm{kg}$ and $5-500,000 \mu \mathrm{g} / \mathrm{kg}$, respectively. Recovery rate for this technique was not determined.

\section{Data Analysis}

Aflatoxin concentrations in market samples and aflatoxins produced on fruits in laboratory assays were quantified in micrograms per kilogram $\left(\mu \mathrm{g} \mathrm{kg}^{-1}\right)$. Total quantity of section Flavi fungi from each assay was calculated as CFU per gram $\left(\mathrm{CFU} \mathrm{g} \mathrm{g}^{-1}\right)$. Compositions of section Flavi communities were described as the percent of the isolates obtained from each fruit sample composed of the A. flavus L strain morphotype (Cotty, 1989), un-delineated S strain morphology fungi (Probst et al., 2007), A. parasiticus and Aspergillus tamarii. Comparisons of both aflatoxin concentrations and fungal populations were performed by Analysis of Variance using general linear models (GLM) and Tukey's HSD mean comparison test as implemented in JMP 11.1.1 (SAS Institute, Cary, NC, United States). Data were tested for normality and, if required, log transformed (aflatoxin and CFU data) to normalize distributions before analyses. All laboratory tests were replicated five times with a complete randomized block design. Percent data were arcsine-transformed to normalize the distributions prior to analyses. However, actual means are presented for clarity. All tests were performed at $\alpha=0.05$.

\section{RESULTS}

\section{Aflatoxin in Fruit}

Significant differences were detected among fruits in aflatoxin concentrations (ANOVA, $F_{6,98}=25.3786, P<0.001$ ), with the highest average aflatoxin $(57 \mu \mathrm{g} / \mathrm{kg})$ in $S$. rautanenii and the lowest in Thespesia indica (3 $\mu \mathrm{g} / \mathrm{kg}$, Table 2). More than $80 \%$ of $S$. rautanenii samples had aflatoxin concentrations above the regulatory limit for food in Zambia $(10 \mu \mathrm{g} / \mathrm{kg})$, with fruits containing as much as $128 \mu \mathrm{g} / \mathrm{kg}$ (Table 2). V. lanciflora and 
T. garckeana also had average aflatoxins above the regulatory limit for Zambia $(12 \mu \mathrm{g} / \mathrm{kg}$ and $11 \mu \mathrm{g} / \mathrm{kg}$, respectively), with 53 and $71 \%$ of fruits having aflatoxins concentrations higher than $10 \mu \mathrm{g} / \mathrm{kg}$, respectively (Table 2). The average aflatoxin concentrations in $P$. curatellifolia $(6 \mu \mathrm{g} / \mathrm{kg})$, Ziziphus spp. $(6 \mu \mathrm{g} / \mathrm{kg})$ and $A$. digitata $(4 \mu \mathrm{g} / \mathrm{kg})$ were all below maximum allowable levels in food in Zambia, although 10\% of the Ziziphus spp. were above the regulatory limit (Table 2).

\section{Fungi From Ground Fruit}

Aspergillus section Flavi was recovered from all wild fruits and consisted of A. parasiticus, A. flavus L strain, S morphotype fungi and A. tamarii (Table 3). In total 422 fungal isolates were characterized to species and/or morphotype. The overall quantities (CFU/g) of Aspergillus section Flavi in the fruits varied (ANOVA, $F_{6,74}=4.7008, P<0.001$, Table 3 ) with the highest in P. curatellifolia (56 CFU/g) and the lowest in T. indica (3 CFU/g). Overall frequencies of Aspergillus section Flavi on fruits differed among the fungi (ANOVA, $F_{3,24}=35.0131, P<0.001$ ), with A. flavus L morphotype most frequent $(77.5 \%, P<0.05)$. When fruit species were considered individually, the A. flavus L strain occurred in the greatest concentrations $(P<0.05)$ on each, except for $V$. lanciflora, where frequencies of A. flavus and A. parasiticus recovered were not significantly different (51.2 and 44.8\%, respectively). Frequencies were similar among fruit species for $S$ morphotype fungi (ANOVA, $F_{6,100}=1.0444, P=0.4169$ ) and A. tamarii (ANOVA, $F_{6,100}=0.8472, P=0.5440$ ). Higher frequencies of $A$. parasiticus were also found on T. garckeana (38.2\%) than all other fruits $(P<0.05$, Table 3$)$, but similar to that recovered from $V$. lanciflora.

\section{Wild Fruits as Substrate for Growth by Aflatoxin-Producers}

Wild fruits differed in ability to support aflatoxin-producer growth as measured by spore production on fruit surfaces (ANOVA, $\left.F_{5,23}=176.2224, P<0.001\right)$, with the highest average spore production on $V$. lanciflora $\left(1.1 \times 10^{9} \mathrm{CFU} / \mathrm{g}\right)$ and no propagules detected on $T$. indica (Table 4). Average spore production across all fruits did not differ among fungi $\left(F_{4,24}=0.0045, P>0.05\right)$. There were significant differences (ANOVA, $F_{5,24}=1740.5680, P<0.001$ ) in $A$. parasiticus NRRL 2999 growth among fruit, with the most propagules produced on $V$. lanciflora $\left(6.1 \times 10^{8} \mathrm{CFU} / \mathrm{g}\right)$ (Table 4). Similarly, the A. flavus S morphotype (AF70; ATCC MYA384) and (A-11612) produced the most propagules on $V$. lanciflora $\left(1.7 \times 10^{9}\right.$ and $1.9 \times 10^{9} \mathrm{CFU} / \mathrm{g}$, respectively) (Table 4). On the other hand, A. minisclerotigenes (A-11611) sporulated most on T. garckeana $\left(6.5 \times 10^{8} \mathrm{CFU} / \mathrm{g}\right)$. None of the fungi produced propagules on T. indica (Table 4).

\section{Wild Fruits as Substrate for Aflatoxin Production}

With the exception of $T$. indica, all fruit species supported production of aflatoxin concentrations greater than $10 \mathrm{mg} / \mathrm{kg}$ during the 7-day growth period (Table 5). On average, there were significant differences among fruits in concentrations of aflatoxins produced (ANOVA, $F_{5,24}=61.9592, P<0.001$ ), with the highest concentrations produced on $T$. garckeana (average $=73,500 \mu \mathrm{g} / \mathrm{kg}$, Table 5). On average across fruit species, concentrations of aflatoxins produced by the six Aspergillus section Flavi did not differ (ANOVA, $F_{4,25}=0.0215, P=0.9990$; Table 5). Among the fungi examined, A. parasiticus produced the highest concentrations of aflatoxins on $S$. rautanenii $(182,000 \mu \mathrm{g} / \mathrm{kg})$ and T. garckeana $(131,000 \mu \mathrm{g} / \mathrm{kg})$ with A. aflatoxiformans producing statistically similar quantities $($ mean $=212,000)$ on T. garckeana; Table 5). A. parasiticus produced less aflatoxins on Ziziphus spp. $(16,100 \mu \mathrm{g} / \mathrm{kg})$, P. curatellifolia $(5,081 \mu \mathrm{g} / \mathrm{kg}), \quad V$. lanciflora $(2,729 \mu \mathrm{g} / \mathrm{kg})$ or T. indica $(P<0.05)$. A. flavus L (AF13), and S (AF70) morphotypes produced similar concentrations on fruits (Table 5). A. minisclerotigenes was the most aflatoxigenic species on Vangueriopsis $(76,604 \mu \mathrm{g} / \mathrm{kg}$; Table 5).

\section{DISCUSSION}

In the current study, aflatoxins were detected in all the examined fruit species (Table 2) with distributions similar to that previously reported for non-cultivated fruits gathered in North America (Boyd and Cotty, 2001). The current report is the first documentation of aflatoxins in wild tropical fruits including S. rautanenii, V. lanciflora, T. garckeana, $P$. curatellifolia, Ziziphus spp., and A. digitata. Although aflatoxin recovery rates are low, our results provide an initial indication that these fruits are a source of aflatoxin exposure and support development of substrate specific methods that might allow more precise quantification of the extent of human exposure resulting from actual consumption patterns. As is the case with crop plants, susceptibility to aflatoxin contamination in wild fruits varies among species (Boyd and Cotty, 2001; Table 2). Samples of S. rautanenii collected during the current study contained aflatoxin concentrations exceeding $125 \mu \mathrm{g} / \mathrm{kg}$, whereas, all T. indica contained $<10 \mu \mathrm{g} / \mathrm{kg}$ total aflatoxins. Differences among fruits in concentrations of aflatoxins may be attributable to chemical composition (Mehl and Cotty, 2013b), variation in structures of communities of Aspergillus section Flavi colonizing the fruits (Mehl et al., 2012), and/or fruit specific processing and storage practices. Although it is not known whether the aflatoxins detected in S. rautanenii were primarily in the seed or pulp, both components of the fruit are important in human diet and would contribute to aflatoxin exposure in Zambia.

Aspergillus section Flavi community structure influences aflatoxin-producing potential of fungi infecting crops and, as a result, the extent of contamination (Probst et al., 2007; Mehl et al., 2012). In wild fruits of Zambia, the A. flavus L morphotype was the most frequent (77.5\%) member of Aspergillus section Flavi (Table 3). High frequencies of A. flavus L morphotype on fruit are not surprising because even though soils in forests and cultivated areas of Zambia are dominated by A. parasiticus (Kachapulula et al., 2017b), the A. flavus L morphotype is a much more competitive plant colonizer. It was unexpected that high amounts of aflatoxins in $S$. rautanenii were associated with high frequencies of the A. flavus L morphotype because, 
TABLE 3 | Distribution of fungi of Aspergillus section Flavi on non-cultivated fruits purchased from local markets in Zambia.

\begin{tabular}{|c|c|c|c|c|c|c|}
\hline Wild fruit species & Samples (\#) & $\% L^{a, b}$ & $\% S$ & $\% \mathbf{P}$ & $\% \mathrm{~T}$ & $\mathrm{CFU} / \mathrm{g}^{\mathrm{c}}$ \\
\hline Adansonia digitata & 9 & $81.9^{A B}$ & $9.8^{\mathrm{A}}$ & $8.3^{\mathrm{BC}}$ & $\mathrm{O}^{\mathrm{A}}$ & 8 \\
\hline Parinari curatellifolia & 17 & $87.5^{\mathrm{AB}}$ & $12.5^{\mathrm{A}}$ & $0^{C}$ & $\mathrm{O}^{\mathrm{A}}$ & 56 \\
\hline Schinziophyton rautanenii & 24 & $97.1^{\mathrm{A}}$ & $2.9^{\mathrm{A}}$ & $0^{C}$ & $\mathrm{O}^{\mathrm{A}}$ & 13 \\
\hline Tamarindus indica & 25 & $88.4^{\mathrm{AB}}$ & $3.6^{\mathrm{A}}$ & $8^{\mathrm{BC}}$ & $\mathrm{O}^{\mathrm{A}}$ & 3 \\
\hline Thespesia garckeana & 20 & $45.3^{C}$ & $13.9^{\mathrm{A}}$ & $38.2^{\mathrm{A}}$ & $2.7^{\mathrm{A}}$ & 10 \\
\hline Vangueriopsis lanciflora & 7 & $51.2^{\mathrm{BC}}$ & $0^{A}$ & $44.8^{A}$ & $\mathrm{O}^{\mathrm{A}}$ & 5 \\
\hline Ziziphus spp. & 12 & $91.3^{\mathrm{AB}}$ & $8.7^{\mathrm{A}}$ & $0^{C}$ & $\mathrm{O}^{\mathrm{A}}$ & 38 \\
\hline Average & & $77.5^{x}$ & $7.3^{Y}$ & $14.2^{Y}$ & $0.4^{Y}$ & 19 \\
\hline
\end{tabular}

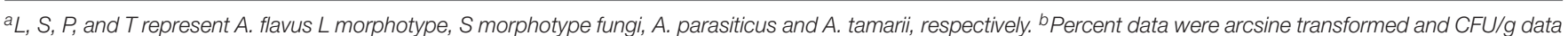

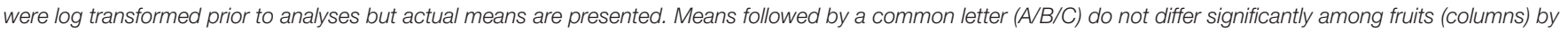
Tukey's HSD test $(\alpha=0.05)$. Average frequencies of fungi across all fruit species followed by a common letter $(X Y)$ do not differ significantly by Tukey's HSD test ( $\alpha=0.05$ ).

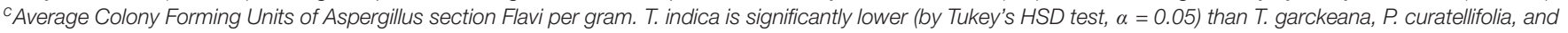
Ziziphus spp. There are no other significant differences.

TABLE 4 | Propagules produced by five Aspergillus section Flavi fungi on inoculated, non-cultivated fruits, gathered in Zambia and purchased in local markets.

Growth of aflatoxin-producers on fruits (CFU/g)

\begin{tabular}{|c|c|c|c|c|c|c|}
\hline & A. parasiticus ${ }^{\mathrm{a}}$ & A. flavus-S & A. flavus $-\mathrm{L}$ & A. minisclerotigenes & A. aflatoxiformans & Average \\
\hline Schinziophyton rautanenii & $1.2 \times 10^{8 \mathrm{~B}(\mathrm{X})}$ & $2.3 \times 10^{6 C(Z)}$ & $2.7 \times 10^{8 \mathrm{~A}(\mathrm{X})}$ & $5.7 \times 10^{7 \mathrm{C}(\mathrm{Y})}$ & $3.1 \times 10^{7 \mathrm{C}(\mathrm{Y})}$ & $9.5 \times 10^{7 \mathrm{C}}$ \\
\hline Thespesia garckeana & $1.6 \times 10^{7 C(z)}$ & $8.7 \times 10^{7 \mathrm{~B}(\mathrm{Y})}$ & $2.2 \times 10^{8 \mathrm{~A}(\mathrm{X})}$ & $6.5 \times 10^{8 \mathrm{~A}(\mathrm{~W})}$ & $1.3 \times 10^{8 \mathrm{~B}(Y)}$ & $2.2 \times 10^{8 B}$ \\
\hline Vangueriopsis lanciflora & $6.1 \times 10^{8 \mathrm{~A}(\mathrm{Y})}$ & $1.7 \times 10^{9 \mathrm{~A}(\mathrm{X})}$ & N/A & $1.5 \times 10^{8 \mathrm{~B}(\mathrm{Z})}$ & $1.9 \times 10^{9 \mathrm{~A}(\mathrm{X})}$ & $1.1 \times 10^{9 \mathrm{~A}}$ \\
\hline Ziziphus spp. & $2.0 \times 10^{6 \mathrm{D}(Y)}$ & $7.3 \times 10^{7 B(X)}$ & $7.3 \times 10^{7 \mathrm{~B}(\mathrm{X})}$ & $4.4 \times 10^{6 \mathrm{D}(Y)}$ & $7.3 \times 10^{6 \mathrm{D}(Y)}$ & $3.2 \times 10^{7 \mathrm{C}}$ \\
\hline
\end{tabular}

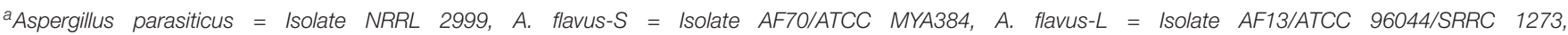
A. minisclerotigenes = Isolate A-11611, Aspergillus aflatoxiformans = Isolate A-11612. Means followed by the same letter (A/B/C) among fruits (Columns) or (W/XY/Z) among fungal species (rows) were not significantly different $(P<0.05)$ by Tukey-Kramer's HSD test. ${ }^{b}$ ND $=$ not detected.

TABLE 5 | Ability of non-cultivated fruits, gathered in Zambia and purchased in local markets, to support aflatoxin production by five aflatoxin producers.

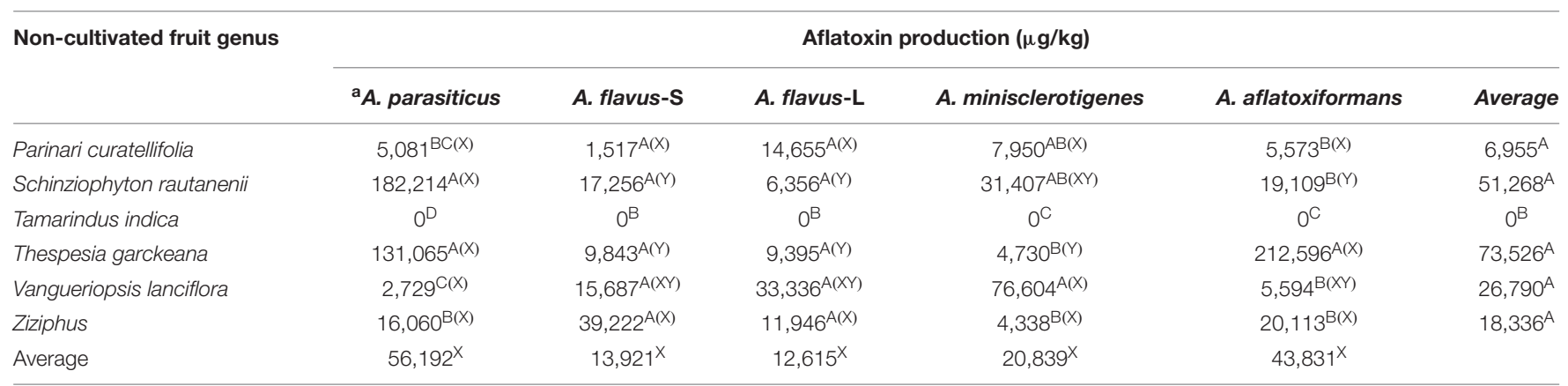

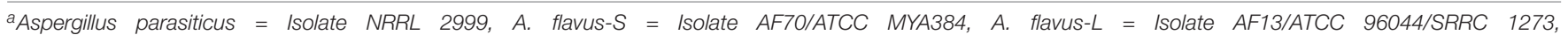
A. minisclerotigenes $=$ Isolate $A-11611, A$. aflatoxiformans $=$ Isolate $A-11612$. Values are means of the results of analyses on five independent solid fermentations (replicates) incubated for 7 days at $31^{\circ} \mathrm{C}$. Means followed by the same letter (A/B/C) among fruits (columns) or (XY) among fungal species or morphotypes were not significantly different $(P<0.05)$ by Tukey-Kramer's HSD test.

most A. flavus L morphotype from Zambia are either atoxigenic or have low aflatoxin-producing potential (Kachapulula et al., 2017a). Similarly, higher levels of aflatoxins were expected in $P$. curatellifolia, due to incidences of over $10 \%$ of the high aflatoxin-producing $S$ morphology fungi (Table 3). It is possible that $S$. rautanenii selects for aflatoxigenic A. flavus L morphotype (Sweany et al., 2011). However, it is more likely that environmental conditions between fruit development and collection predisposed $S$. rautanenii to high aflatoxin concentrations and P. curatellifolia to low concentrations. On the other hand, V. lanciflora and T. garckeana had appreciable levels of S morphotype fungi and/or A. parasiticus (Table 3) and as expected (Cotty et al., 2008), high concentrations of aflatoxins (Table 2).

The suitability of fruits gathered from the wild as substrates for growth of aflatoxigenic fungi was evaluated by quantifying 
propagule production by reference aflatoxigenic fungi. All tested fruits supported growth except T. indica (Table 4). Both cultivated (Mehl and Cotty, 2013a) and non-cultivated plants (Boyd and Cotty, 2001) are susceptible to infection by aflatoxin-producing fungi. Invasion of host tissues requires plantdegrading enzymes, ability to evade or suppress host defenses, and capacity to overcome plant antimicrobial compounds (Agrios, 2005). In the current study, V. lanciflora supported the greatest growth by all aflatoxigenic fungi. On the other hand, even though low amounts of Aspergillus section Flavi were found in $T$. indica market samples (Table 3), growth by the reference aflatoxin-producers on $T$. indica was not detected (Table 4). Phenolic antioxidants from $T$. indica have antifungal properties (Luengthanaphol et al., 2004; Sudjaroen et al., 2005). These antioxidants may be responsible for low fungal growth on T. indica. Tamarindus indica is also known to contain a number of organic acids, including tartaric acid, which causes the fruit's characteristic sour taste (Rao and Mathew, 2012). Tartaric acid is known to have antifungal activity against several species of fungi, including A. flavus (Hassan et al., 2015). Tartaric acid and other organic acids may have contributed to the low fungal growth observed in the current study on $T$. indica. Results of the current study suggest that $T$. indica is a low risk aflatoxin food. However, all other examined wild fruits supported growth by aflatoxin-producers and therefore potential measures for aflatoxin mitigation might include strategies for preventing fungal growth.

Aflatoxin-producers may grow on substrates without producing aflatoxins. Aflatoxin production is dependent on environmental conditions (Cotty and Jaime-Garcia, 2007; Kachapulula et al., 2017a) and substrate nutritional content (Mehl and Cotty, 2013b). Fruit suitability for growth of aflatoxinproducers contributes to fruit vulnerability. However, the quantity of Aspergillus section Flavi on market samples was not significantly correlated with the quantity of aflatoxins in those fruits (unpublished observations). This suggests factors other than just support of growth of Aspergillus section Flavi, such as environmental conditions, toxigenicity of infecting fungi and/or handling (Cotty and Jaime-Garcia, 2007; Kachapulula et al., 2017a), dictated the extent of contamination observed in the wild fruits during the study period in Zambia.

Inoculation of fruits with known aflatoxin-producers under conditions conducive for aflatoxin production provides insight into innate capacity to become contaminated. The fruits varied widely in ability to support aflatoxin biosynthesis and the fruit most vulnerable to contamination was dependent on the aflatoxin-producing species. One fruit ( $T$. indica) supported no aflatoxin production in laboratory inoculation experiments. However, very low concentrations $(<10 \mu \mathrm{g} / \mathrm{kg})$ were detected in market samples. So there is some risk of aflatoxin exposure associated with consumption of $T$. amarindus. Aflatoxins in market Tamarindus may reflect conditions not evaluated in the inoculation tests including aflatoxin formation during fruit development, in association with insect damage, or as a result of long periods of poor storage (Boyd and Cotty, 2001; Cotty et al., 2008). The other species evaluated during laboratory inoculation experiments became contaminated with very high concentrations (Table 5). Even fruits for which market samples were safe for consumption ( $P$. curatellifolia and Ziziphus spp., Table 2) developed high (>6,000 and >18,000 $\mu \mathrm{g} / \mathrm{kg}$, respectively) concentrations of aflatoxins after inoculation with aflatoxin-producers (Table 5). The second largest concentrations of aflatoxin observed (over $180,000 \mu \mathrm{g} / \mathrm{kg}$ total aflatoxins) resulted from inoculation of the most frequently contaminated fruit from the market (S. rautanenii) with $A$. parasiticus, the most common aflatoxin producer in Zambia (Kachapulula et al., 2017b). The results suggest that assessment of fruit vulnerability to contamination should include assessment of both frequencies of specific aflatoxin-producers in the habitat and the suitability of the fruit for contamination by the resident fungi. An additional element important in evaluating fruit vulnerability to contamination not investigated in the current study, is anatomical change during fruit development. In pistachio, early splitting of the hull results in higher quantities of aflatoxins and aflatoxin-producing fungi (Doster and Michailides, 1994; Hadavi, 2005). In almonds, amounts of fungi associated with the crop are highest during hull splitting (Ortega-Beltran et al., 2018). It is possible that for some fruit species additional entry points were created during postharvest handling and the laboratory inoculation process, resulting in increases in vulnerability to the contamination process. This further emphasizes the need for careful fruit handling after harvest. For other fruits examined in the current study, such as $T$. indica, the laboratory handling did not result in aflatoxin increases suggesting that regardless of handling, the fruit retained low susceptibility to aflatoxin contamination. The current study was the first to quantify both the infecting fungi and the ability of fruit from Zambia's diverse forest to market system to support aflatoxin biosynthesis. Although consumers will typically not pick and eat fruits with profuse fungal growth as in Figure 3, the current study indicates many wild fruits support growth and aflatoxin production, and as such, proper handling of the foods is needed.

Aflatoxin-producing potentials of infecting fungal communities may have modulated contamination of wild fruits of P. curatellifolia and Ziziphus spp. in the current study. $P$. curatellifolia and Ziziphus spp. supported high aflatoxin concentrations when inoculated, but fruits collected from markets were also most frequently infected by the A. flavus-L morphotype (Table 3), which in Zambia, is primarily either atoxigenic or of low aflatoxigenicity (Kachapulula et al., 2017a). The low aflatoxin content observed in market samples of these two fruit species thus does not result from innate resistance. The low aflatoxin concentrations may result from a combination of safe handling and storage (Kachapulula et al., 2017a), limited entry points for aflatoxin-producing fungi (Doster and Michailides, 1994; Hadavi, 2005) and a fungal community with low average aflatoxigenicity (Probst et al., 2007, 2010; Cotty et al., 2008). The use of atoxigenic biocontrol agents to modulate Aspergillus fungal communities associated with fruits, as has been done in pistachios and almonds (Cotty et al., 2007; Bandyopadhyay et al., 2016), might reduce incidences of 
aflatoxin-producers and resulting aflatoxin contamination, even where natural anatomical openings in fruits are unavoidable.

In the current study, with the exception of $T$. indica, all wild fruits either had aflatoxin levels above regulatory limits for Zambia, or were suitable substrates for growth and aflatoxin production by aflatoxigenic fungi. Reducing concentrations of aflatoxins in consumed wild fruits may be an important aspect of minimizing overall aflatoxin exposure for Zambian populations. Aflatoxin concentrations in some fruits appear to be a result of environmental conditions and infecting fungi, while for others, innate immunity appears to be the major contributor to contamination patterns. Aflatoxin concentrations in gathered fruits can be limited by not collecting insect damaged fruits, avoiding fruits with conspicuous openings, picking from bearing plants rather than collecting off the ground, and synchronizing gathering periods to precede periodic events such as annual or biannual rains (Doster and Michailides, 1994; Boyd and Cotty, 2001; Hadavi, 2005; Garber et al., 2013). After collection, aflatoxin concentration increases can be limited by proper drying and dry storage. Future research should focus on developing baseline information and practical culturally acceptable techniques for limiting contamination in non-cultivated fruits that are gathered, marketed, and consumed in Zambia. Future research should also look into the possibility of using atoxigenic A. flavus for biological control of aflatoxins, especially where attempts are underway to domesticate wild fruit species. Biological control with atoxigenic strains of $A$. flavus is the most effective control method against aflatoxin contamination (Cotty et al., 2007; Bandyopadhyay et al., 2016). Restricting gathering to areas in close proximity to agricultural fields treated with an atoxigenic strain based biocontrol product may also serve to reduce quantities of aflatoxins associated with the gathered fruits.

\section{REFERENCES}

Agrios, G. N. (2005). Plant Pathology, 5th Edn. San Diego, CA: Academic Press. Akinnifesi, F. K., Kwesiga, F., and Mhango, T. (2006). Towards the development of miombo fruit trees as commercial tree crops in southern Africa. For. Trees Livelihoods 16, 103-121. doi: 10.1080/14728028.2006.975 2548

Akinnifesi, F. K., Kwesiga, F. R., Mhango, J., Mkonda, A., Chilanga, T., and Swai, R. (2002). Domesticating priority, miombo indigenous fruit trees as a promising livelihood option for small-holder farmers in Southern Africa. Acta Hortic. 632, 15-30. doi: 10.17660/actahortic.2004.632.1

Akinnifesi, F. K., Sileshi, G., Ajayi, O. C., Chirwa, P. W., Kwesiga, F. R., and Harawa, R. (2008). Contributions of agroforestry research and development to livelihood of smallholder farmers in Southern Africa: fruit, medicinal, fuelwood and fodder tree systems. Agric. J. 3, 76-88.

Bandyopadhyay, R., Ortega-Beltran, A., Akande, A., Mutegi, C., Atehnkeng, J., Kaptoge, L., et al. (2016). Biological control of aflatoxins in Africa: current status and potential challenges in the face of climate change. World Mycotoxin J. 9, 771-789. doi: 10.3920/wmj2016.2130

Benhura, C., Kugara, J., and Muchuweti, M. (2015). Drying kinetics of syrup of Parinari curatellifolia fruit and cereal based product, zvambwa. J. Food Sci. Technol. 52, 4965-4974. doi: 10.1007/s13197-014-1616-z

Boyd, M. L., and Cotty, P. J. (2001). Aspergillus flavus and aflatoxin contamination of leguminous trees of the sonoran desert in Arizona. Phytopathology 91, 913-919. doi: 10.1094/PHYTO.2001.91.9.913

Buchmann, C., Prehsler, S., Hartl, A., and Vogl, C. R. (2010). The importance of baobab (Adansonia digitata L.) in rural West African subsistence-suggestion of a cautionary approach to international market export of baobab fruits. Ecol. Food Nutr. 49, 145-172. doi: 10.1080/03670241003766014

\section{DATA AVAILABILITY}

The datasets generated for this study are available on request to the corresponding author.

\section{AUTHOR CONTRIBUTIONS}

$\mathrm{PK}, \mathrm{RB}$, and PC contributed to conception and design of the study. PK performed the statistical analyses and wrote the first draft of the manuscript. All authors contributed to the manuscript revision, and read and approved the submitted version.

\section{FUNDING}

This work was supported by the United States Agency for International Development (USAID, Grant No. EEM-G-00-040003-00000); Borlaug Leadership Enhancement in Agriculture Program (Borlaug LEAP) through a grant to the University of California-Davis by the United States Agency for International Development (Borlaug LEAP Agreement Number 016258-131); United States Department of Agriculture (USDA) Agricultural Research Service (CRIS project 2020-42000-020-00D); Foreign Agricultural Service (Grant No. TACR14075); and the Bill and Melinda Gates Foundation (Grant No. OPP1007117).

\section{ACKNOWLEDGMENTS}

We thank Austin Klein for his excellent technical assistance.

Buchwald-Werner, S., and Bischoff, F. (2011). "Natural products-market development and potentials," in Industrial Scale Natural Products Extraction, eds. H. J. Bart and S. S. Pilz (Weinheim: Wiley-VCH Verlag GmbH \& Co. KGaA), 247-267. doi: 10.1002/9783527635122.ch8

Chadare, F. J., Linnemann, A. R., Hounhouigan, J. D., Nout, M. J. R., and Boekel, M. V. (2008). Baobab food products: a review on their composition and nutritional value. Crit. Rev. Food Sci. Nutr. 49, 254-274. doi: 10.1080/ 10408390701856330

Cotty, P. J. (1988). Aflatoxin and sclerotial production by Aspergillus flavus: influence of pH. Phytopathology 78, 1250-1253.

Cotty, P. J. (1989). Virulence and cultural characteristics of two Aspergillus flavus strains pathogenic on cotton. Phytopathology 79, 808-814.

Cotty, P. J. (1994). Comparison of four media for the isolation of Aspergillus flavus group fungi. Mycopathologia 125, 157-162. doi: 10.1007/bf01146521

Cotty, P. J., Antilla, L., and Wakelyn, P. J. (2007). "Competitive exclusion of aflatoxin producers: farmer driven research and development," in Biological Control: A Global Perspective, eds C. Vincent, N. Goettel, and G. Lazarovitis (Oxfordshire: CAB International), 241-253.

Cotty, P. J., and Cardwell, K. F. (1999). Divergence of West African and North American communities of Aspergillus section Flavi. Appl. Environ. Microbiol. 65, 2264-2266.

Cotty, P. J., and Jaime-Garcia, R. (2007). Influences of climate on aflatoxinproducing fungi and aflatoxin contamination. Int. J. Food Microbiol. 119, 109-115. doi: 10.1016/j.ijfoodmicro.2007.07.060

Cotty, P. J., Probst, C., and Jaime-Garcia, R. (2008). "Etiology and management of aflatoxin contamination," in Mycotoxins: Detection Methods, Management, Public Health and Agricultural Trade, eds J. F. Leslie, R. Bandyopadhyay, and A. Visconti (Oxfordshire: CAB International), 287-299. doi: 10.1079/ 9781845930820.0287 
Doster, M. A., and Michailides, T. J. (1994). Aspergillus molds and aflatoxins in pistachio nuts in California. Phytopathology 84, 583-590.

Ebifa-Othieno, E., Mugisha, A., Nyeko, P., and Kabasa, J. D. (2017). Knowledge, attitudes and practices in tamarind (Tamarindus indica L.) use and conservation in Eastern Uganda. J. Ethnobiol. Ethnomed. 13:5. doi: 10.1186/s13002-0160133-8

Frisvad, J. C., Hubka, V., Ezekiel, C. N., Hong, S. B., Novakova, A., Chen, A. J., et al. (2019). Taxonomy of Aspergilus section Flavi and their production of aflatoxins, ochratoxins and other mycotoxins. Stud. Mycol. 93, 1-63. doi: 10.1016/j.simyco. 2018.06.001

Garber, N. P., Allen, J., and Cotty, P. J. (2013). Human exposure to aflatoxin in mesquite pod flour produced for personal consumption, cottage industry, and commercial markets in southeastern arizona. Phytopathology 103, 47-48.

Gong, Y., Hounsa, A., and Egal, S. (2004). Postweaning exposure to aflatoxin results in impaired child growth: a longitudinal study in benin, West Africa. Environ. Health Perspect. 112, 1334-1338. doi: 10.1289/ehp.6954

Hadavi, E. (2005). Several physical properties of aflatoxin-contaminated pistachio nuts: application of BGY fluorescence for separation of aflatoxin-contaminated nuts. Food Add. Cont. 22, 1144-1153. doi: 10.1080/02652030500306976

Hassan, R., El-Kadi, S., and Sand, M. (2015). Effect of some organic acids on some fungal growth and their toxins production. Int. J. Adv. Biol. 2, 1-11.

Horn, B. W., and Dorner, J. W. (1998). Soil populations of Aspergillus species from section Flavi along a transect through peanut-growing regions of the United States. Mycologia 90, 767-776. doi: 10.1080/00275514.1998.1202 6969

Juliani, H. R., Koroch, A. R., Simon, J. E., and Wamulwange, C. (2007). Mungongo cold pressed oil (Schinziophyton rautanenii): a new natural product with potential cosmetic applications. Acta Hort. 756, 407-412. doi: 10.17660/ actahortic.2007.756.43

Kachapulula, P. W., Akello, J., Bandyopadhyay, R., and Cotty, P. J. (2017a). Aflatoxin contamination of groundnut and maize in Zambia: observed and potential concentrations. J. Appl. Microbiol. 6, 1471-1482. doi: 10.1111/jam. 13448

Kachapulula, P. W., Akello, J., Bandyopadhyay, R., and Cotty, P. J. (2017b). Aspergillus section Flavi community structure in Zambia influences aflatoxin contamination of maize and groundnut. Int. J. Food Microbiol. 261, 49-56. doi: 10.1016/j.ijfoodmicro.2017.08.014

Kalaba, F. K., Chirwa, P. W., and Prozesky, H. (2009). The contribution of indigenous fruit trees in sustaining rural livelihoods and conservation of natural resources. J. Hort. For. 1, 1-6.

Klich, M. A., and Pitt, J. I. (1988). Differentiation of Aspergillus flavus from a. parasiticus and other closely related species. Trans. Br. Mycol. Soc. 91, 99-108. doi: 10.1016/s0007-1536(88)80010-x

Lewis, L., Onsongo, M., and Njapau, H. (2005). Aflatoxin contamination of commercial maize products during an outbreak of acute aflatoxicosis in eastern and central Kenya. Environ. Health Perspect. 113, 1763-1767. doi: 10.1289/ehp. 7998

Liu, Y., Chang, C. H., Marsh, G. M., and Wu, F. (2012). Population attributable risk of aflatoxin-related liver cancer: systematic review and meta-analysis. Eur. J. Cancer 48, 2125-2136. doi: 10.1016/j.ejca.2012.02.009

Luengthanaphol, S., Mongkholkhajornsilp, D., Douglas, S., Douglas, P. L., Pengsopa, L., and Pongamphai, S. (2004). Extraction of antioxidants from sweet thai tamarind seed coat-preliminary experiments. J. Food Eng. 63, 247-252. doi: 10.1016/j.jfoodeng.2003.07.006

Maroyi, A. (2011). An ethnobotanical survey of medicinal plants used by the people in Nhema communal area, zimbabwe. J. Ethnopharmacol. 136, 347-354. doi: $10.1016 /$ j.jep.2011.05.003

Maruza, I. M., Musemwa, L., Mapurazi, S., Matsika, P., Munyati, V. T., and Ndhleve, S. (2017). Future prospects of Ziziphus mauritiana in alleviating household food insecurity and illnesses in arid and semi-arid areas: a review. World Dev. Perspect. 5, 1-6. doi: 10.1016/j.wdp.2017.01.001

Mehl, H. L., and Cotty, P. J. (2013b). Nutrient environments influence competition among Aspergillus flavus genotypes. Appl. Environ. Microbiol. 79, 1473-1480. doi: 10.1128/AEM.02970-12

Mehl, H. L., and Cotty, P. J. (2013a). Influence of plant host species on intraspecific competition during infection by Aspergillus flavus. Plant Pathol. 62, 1310-1318. doi: 10.1111/ppa.12038

Mehl, H. L., Jaime, R., and Callicott, K. A. (2012). Aspergillus flavus diversity on crops and in the environment can be exploited to reduce aflatoxin exposure and improve health. Ann. N. Y. Acad. Sci. 1273, 7-17. doi: 10.1111/j.1749-6632. 2012.06800.x

Njana, M. A., Kajembe, G. C., and Malimbwi, R. E. (2013). Are miombo woodlands vital to livelihoods of rural households? evidence from Urumwa and surrounding communities, tabora, tanzania. For. Trees Livelihoods 22, 124-140. doi: $10.1080 / 14728028.2013 .803774$

Ortega-Beltran, A., Moral, J., Puckett, R. D., Morgan, D. P., Cotty, P. J., and Michailides, T. J. (2018). Fungal communities associated with almond throughout crop development: implications for aflatoxin biocontrol management in California. PLoS One 13:e0199127. doi: 10.1371/journal.pone.0199127

Pildain, M. B., Frisvad, J. C., Vaamonde, G., Cabral, D., Varga, J., and Samson, R. A. (2008). Two novel aflatoxin-producing Aspergillus species from argentinean peanuts. Int. J. Syst. Evol. Microbiol. 58, 725-735. doi: 10.1099/ijs.0.65123-0

Probst, C., Njapau, H., and Cotty, P. J. (2007). Outbreak of an acute aflatoxicosis in Kenya in 2004: identification of the causal agent. Appl. Environ. Microbiol. 73, 2762-2764. doi: 10.1128/aem.02370-06

Probst, C., Schulthess, F., and Cotty, P. J. (2010). Impact of Aspergillus section Flavi community structure on the development of lethal levels of aflatoxins in kenyan maize (Zea mays). J. Appl. Microbiol. 108, 600-610. doi: 10.1111/j.1365-2672. 2009.04458.x

Rahul, J., Jain, M. K., and Singh, S. P. (2015). Adansonia digitata L.(baobab): a review of traditional information and taxonomic description Asian. Pac. J. Trop. Biomed. 5, 79-84. doi: 10.1016/s2221-1691(15)30174-x

Rao, Y. S., and Mathew, K. M. (2012). "Tamarind," in Handbook of Herbs and Spices, ed. K. V Peter, (Sawston: Woodhead Publishing).

Reddy, B. N., and Raghavender, C. R. (2007). Outbreaks of aflatoxicoses in India. Afr. J. Food Agric. Nutr. Dev. 7:5.

Singh, P., and Cotty, P. J. (2019). Characterisation of Aspergilli from dried red chilies (Capsicum spp.): insights into the etiology of aflatoxin contamination. Int. J. Food Microbiol. 289, 145-153. doi: 10.1016/j.ijfoodmicro.2018.08.025

Sudjaroen, Y., Haubner, R., and Würtele, G. (2005). Isolation and structure elucidation of phenolic antioxidants from Tamarind (Tamarindus indica L.) seeds and pericarp. Food Chem. Toxicol. 43, 1673-1682. doi: 10.1016/j.fct.2005. 05.013

Sweany, R. R., Damann, K. E., and Kaller, M. D. (2011). Comparison of soil and corn kernel Aspergillus flavus populations: evidence for niche specialization. Phytopathology 101, 952-959. doi: 10.1094/PHYTO-09-10-0243

Turner, P. C., Moore, S. E., Hall, A. J., Prentice, A. M., and Wild, C. P. (2003). Modification of immune function through exposure to dietary aflatoxin in Gambian children. Environ. Health Perspect. 111, 217-220. doi: 10.1289/ehp. 5753

Van Egmond, H. P., Schothorst, R. C., and Jonker, M. A. (2007). Regulations relating to mycotoxins in food. Anal. Bioanal. Chem. 389, 147-157. doi: 10. 1007/s00216-007-1317-9

Vermaak, I., Paulin, G., Kamatou, P., Komane-Mofokeng, B., Viljoen, A. M., and Beckett, K. (2011). African seed oils of commercial importance-cosmetic applications. South Afr. J. Bot. 77, 920-933. doi: 10.1016/j.sajb.2011. 07.003

Williams, J. H., Phillips, T. D., Jolly, P. E., Stiles, J. K., Jolly, C. M., and Aggarwal, D. (2004). Human aflatoxicosis in developing countries: a review of toxicology, exposure, potential health consequences, and interventions. Am. J. Clin. Nutr. 80, 1106-1122. doi: $10.1093 /$ ajcn/80.5.1106

Wu, F. (2014). Global impacts of aflatoxin in maize: trade and human health. World Mycotoxin J. 8, 137-142. doi: 10.3920/wmj2014.1737

Zimba, N., Wren, S., and Stucki, A. (2005). Three major tree nut oils of southern central africa: their uses and future as commercial base oils. Int. J. Aromather. 15, 177-182. doi: 10.1016/j.ijat.2005.10.009

Conflict of Interest Statement: The authors declare that the research was conducted in the absence of any commercial or financial relationships that could be construed as a potential conflict of interest.

Copyright $\odot 2019$ Kachapulula, Bandyopadhyay and Cotty. This is an open-access article distributed under the terms of the Creative Commons Attribution License (CC BY). The use, distribution or reproduction in other forums is permitted, provided the original author(s) and the copyright owner(s) are credited and that the original publication in this journal is cited, in accordance with accepted academic practice. No use, distribution or reproduction is permitted which does not comply with these terms. 